\title{
COVID-19 in HIV: a Review of Published Case Reports
}

\author{
Zoya Morani ${ }^{1}$ - Saumil Patel ${ }^{2}$. Sudeshna Ghosh ${ }^{3} \cdot$ Falah Abu Hassan $^{4} \cdot$ Shriya Doreswamy $^{5} \cdot$ Sandeep Singh $^{6}$ (D) \\ Venkata Neelima Kothapudi ${ }^{7} \cdot$ Rupak Desai $^{8}$
}

Accepted: 13 October 2020 / Published online: 2 November 2020

(C) The Author(s) 2020

\begin{abstract}
Patients with COVID-19 present with a myriad of comorbidities. An immunocompromised state like HIV in patients with COVID-19 can be life-threatening. We searched PubMed/Medline, Scopus, and Web of Science for case reports and case series about COVID-19 in HIV patients. We finally reviewed 20 case reports including cases of 43 patients with HIV and COVID-19. The mean age of 43 adult patients was $51.56 \pm 27.56$ years (range $24-76$ years). Of these, 30 were male $(69.77 \%), 11$ were female $(25.58 \%)$, and 2 were transgender $(4.65 \%)$. A total of 25 patients $(58.14 \%)$ were above 50 years of age. The most common cardiovascular comorbidities were hypertension and hyperlipidemia (48.8\%), diabetes (20.93\%), and morbid obesity (11.63\%). Out of 43 HIV patients with COVID-19, 6 resulted in death (13.95\%). All the patients who died were elderly above 50 years and required mechanical ventilation. HIV patients infected with COVID-19 had a high mortality rate. A high burden of pre-existing comorbidities and an advanced age in these patients make them prone to disease progression and worse outcomes.
\end{abstract}

Keywords COVID-19 $\cdot$ HIV $\cdot$ SARS-CoV-2

\section{Introduction}

Coronavirus disease (COVID-19), caused by the novel SARS-CoV-2 virus, was declared a global pandemic by the World Health Organization on 11 March 2020. Earlier it has caused diseases like Middle East respiratory syndrome

This article is part of the Topical Collection on Covid-19

Sandeep Singh

sandeepkcsingh@gmail.com

1 Washington University of Health and Science, San Pedro, Belize

2 Carefirst Primary and Wellness Center, Dallas, TX, USA

3 UT South Western Medical Center, Dallas, TX, USA

4 Princess of Wales Hospital, Bridgend, UK

5 Vydehi Institute of Medical Sciences and Research Center, Bangalore, India

6 Department of Clinical Epidemiology, Biostatistics and Bioinformatics, Amsterdam University Medical Center, AMC, Amsterdam, Netherlands

7 Department of Medicine, Gandhi Medical College, Secunderabad, Telangana, India

8 Division of Cardiology, Atlanta VA Medical Center, Decatur, GA, USA
(MERS) in Saudi Arabia in 2012 and severe acute respiratory syndromes (SARS) in China in 2002. The single-stranded RNA genome virus has overwhelmed the healthcare system all across the world. People living with human immunodeficiency virus (HIV), advanced age ( $>60$ years), hypertension (HTN), and diabetes mellitus (DM) are at an increased risk of mortality and morbidity. HIV (human immunodeficiency virus) pandemic coexisting with another pandemic like COVID19 is called syndemic. This group of HIV-positive individuals, who are unable to practice socialdistancing, have limited access to healthcare, and are prone to drug abuse, will be severely affected. The antiretroviral therapy (ART) has helped in prolonging the lifespan of HIV-positive patients, but the concurrent occurrence of COVID-19 and HIV is presenting unique challenges to the management of these patients. Difficulty in the timely refill of ART medications, a restricted visit to doctors, increased stressors like loneliness, loss of jobs, and fear of homelessness could culminate in substance abuse, a rise in acquired immunodeficiency syndrome (AIDS)-related diseases, and psychiatric problems [1]. The condition could be worse in areas with the already overburdened healthcare system and diversion of public health resources to combat COVID-19. It can make this vulnerable population face unprecedented challenges to maintain their continuity of care [2]. With no cure at hand, practicing social distancing is playing a major role in minimizing the spread of the coronavirus 
infection but can result in decreased adherence to ART therapy and the health outcomes of these patients will take a downhill course [3]. Therefore, we aim to systematically review all published cases of HIV patients with COVID-19 and related clinical correlates and outcomes.

\section{Methods}

We searched PubMed/Medline, Web of Science, and Scopus until 1 August 2020 for case reports and case series using the following keywords: COVID-19, SARS-CoV-2, HIV, and human immunodeficiency virus. All published case reports included in the final analysis were in the English language. Our search identified 167 studies in total. After removing the duplicates and selecting case reports or case series with individual patient-level data, we found 23 articles. Due to a lack of data, we further excluded 3 articles and finally include 20 articles [4-23]. Continuous variables were presented as means \pm standard deviations and categorical data as absolute values and percentages. All data extraction and descriptive analysis were performed using Microsoft Excel.

\section{Results}

We identified 23 articles through our search from which we excluded 3 due to lack of data. Using 20 articles we selected, a total of 43 patients were analyzed. The mean age of the patients was $51.56 \pm 27.56$ (range 24-76 years). Of the 43 patients, 30 were male $(69.77 \%)$, 11 were female $(25.58 \%)$, and 2 were transgender $(4.65 \%)$. The race was not included in the analysis due to it not being reported in the data. The majority of the cases were from the USA $(58.14 \%)$, followed by China (13.95\%), the UK (6.98\%), Iran (4.65\%), South Korea (4.65\%), Austria (2.33\%), Cyprus (2.33\%), Italy (2.33\%), Japan (2.33\%), and Singapore (2.33\%) (Table 1). A total of 25 patients had cardiovascular/pulmonary comorbidities (58.14\%), the most predominant one being HTN in 14 patients $(32.56 \%)$ out of which less than half had hyperlipidemia (HLD). Of 44 patients, 9 had diabetes mellitus (20.93\%), 5 had the chronic obstructive pulmonary disease (11.63\%), and 3 patients had a history of atrial fibrillation $(6.98 \%)$.

In terms of presenting symptoms, out of 43 patients, 32 presented with fever $(74.42 \%), 29$ presented with cough $(67.44 \%), 9$ presented with diarrhea $(20.93 \%), 8$ reported headaches $(18.60 \%), 11$ had tachycardia $(25.58 \%), 16$ had shortness of breath/dyspnea (37.21\%), 2 patients had hypoxia (4.65\%), 1 reported pneumonia $(2.33 \%), 5$ patients presented with fatigue $(11.63 \%), 2$ presented with vomiting $(4.65 \%), 1$ reported weakness $(2.33 \%), 5$ reported myalgia $(11.63 \%), 1$ other patient reported anosmia and ageusia $(2.33 \%)$, and a patient also presented with a sore throat. Of 32 patients who presented with fever, 2 had an upper respiratory tract infection and 3 had a lower respiratory tract infection. Out of the 29 (85.29\%) patients presenting with cough, 8 reported having a dry cough.

When looking at the contact history of the 43 patients, 34 patients $(79.07 \%)$ had no contact history reported. Out of the 9 patients who did have a contact history, 2 denied any sick contacts, 1 had a friend with flu symptoms, 1 had an indirect exposure to a COVID-19-positive patient, 1 of the patients was a pharmacist exposed to COVID-19, another was a sex worker, 1 had dinner 5 days prior with a COVID-19-positive person, another took a trip to Florida, and lastly 1 of the exposed patients was a healthcare worker. There was only one case that reported the meantime from exposure to infection of 12 days. CD4 counts were reported in 32 patients of which, 17 (53.13\%) had a CD4 count lower than the normal range $(<$ 500 cells $\left./ \mathrm{mm}^{3}\right)$. Nine $(20.93 \%)$ of the patients had undetectable HIV-RNA (copies/ml) or viral load. Of 30 cases reporting $\mathrm{SPO}_{2}$ data, $13(45.1 \%$ ) had oxygen saturation less than $95 \%$ at the time of admission.

Out of 43 HIV patients with COVID-19, 6 (13.95\%) patients died during hospitalization, while the remaining 37 $(86.05 \%)$ recovered (Table 2$)$. The mean age of the patients that resulted in death was $63.5 \pm 12.5$ (range 52-76). Of the 6 that died, 5 had bilateral ground-glass opacities on computed tomography scan/chest x-ray, had low oxygen saturation, required mechanical ventilation, and their hospitalization ranged from 1 to 14 days. Of the 37 recovered, 8 patients were on hydroxychloroquine (HCQ) and 1 patient was on chloroquine (CQ). All the patients were on different antiretroviral therapy regimens.

\section{Discussion}

The key findings of the current review suggest that HIV patients with COVID-19 infection have a high burden of cardiovascular comorbidities. Furthermore, most of the patients were elderly and male. The most common presenting symptoms were fever, cough, and shortness of breath as reported in COVID-19 patients. Besides, the majority of HIV patients with COVID-19 infection were on ART therapy. The patients who did not recover were mostly elderly (> 50 years) and had cardiovascular comorbidities including HTN, DM, or both. A study by Shahid et al. stated that the older COVID-19 patients with comorbidities such as DM have an increased risk of mortality [24]. Of 6 patients who died, 5 received HCQ with some having a combination of HCQ and/or azithromycin (AZM) and/or 3rd-generation cephalosporins. Of the 37 recovered patients, 11 were on ritonavir (RTV), and 8 of which were on lopinavir (LPV) as well. A study by $\mathrm{Yu}$ and colleagues found that influenza-coinfected patients taking lopinavir/ritonavir(LPV/r) treatment had faster pneumonia recovery than those who did not [25]. 


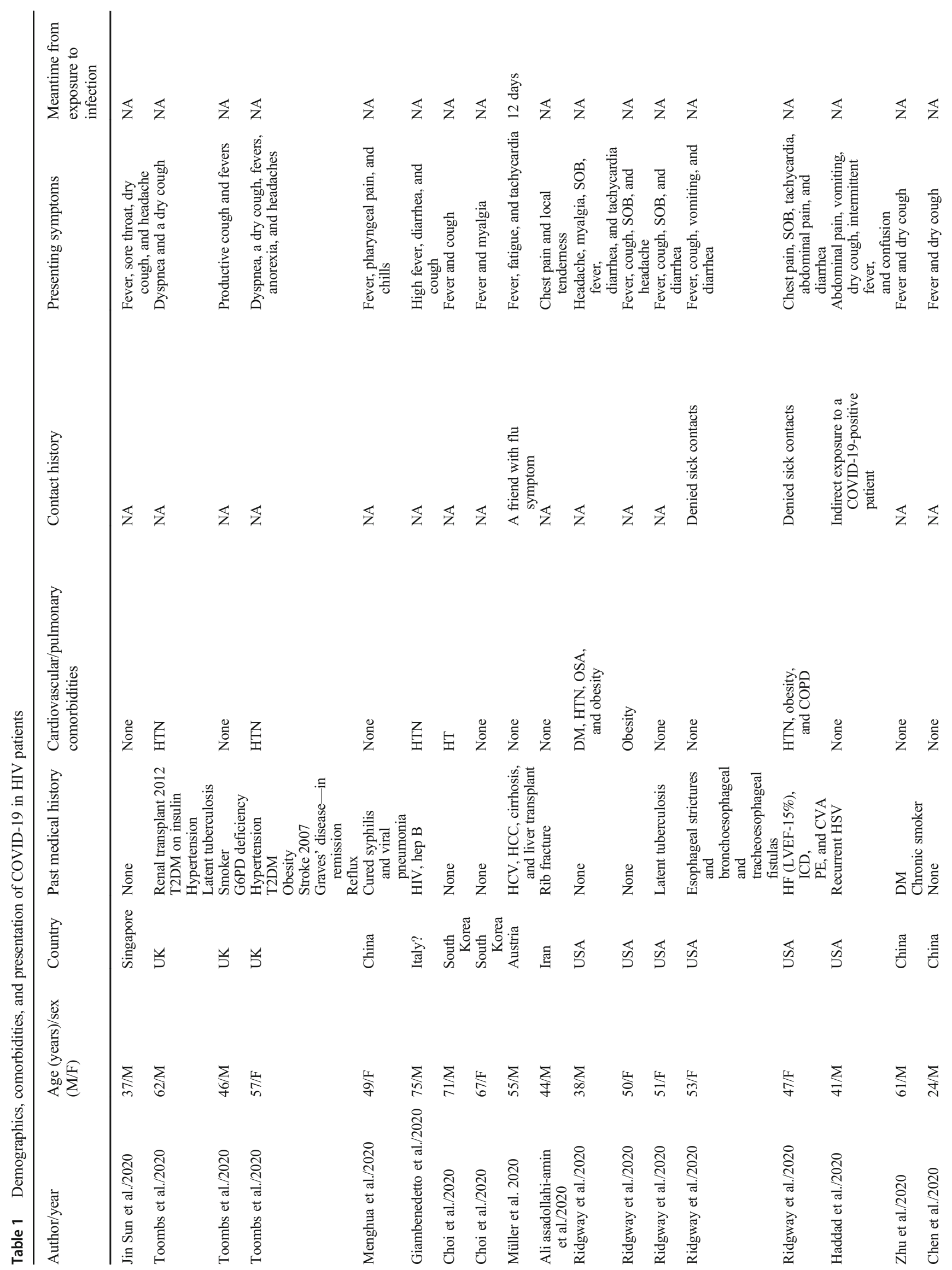




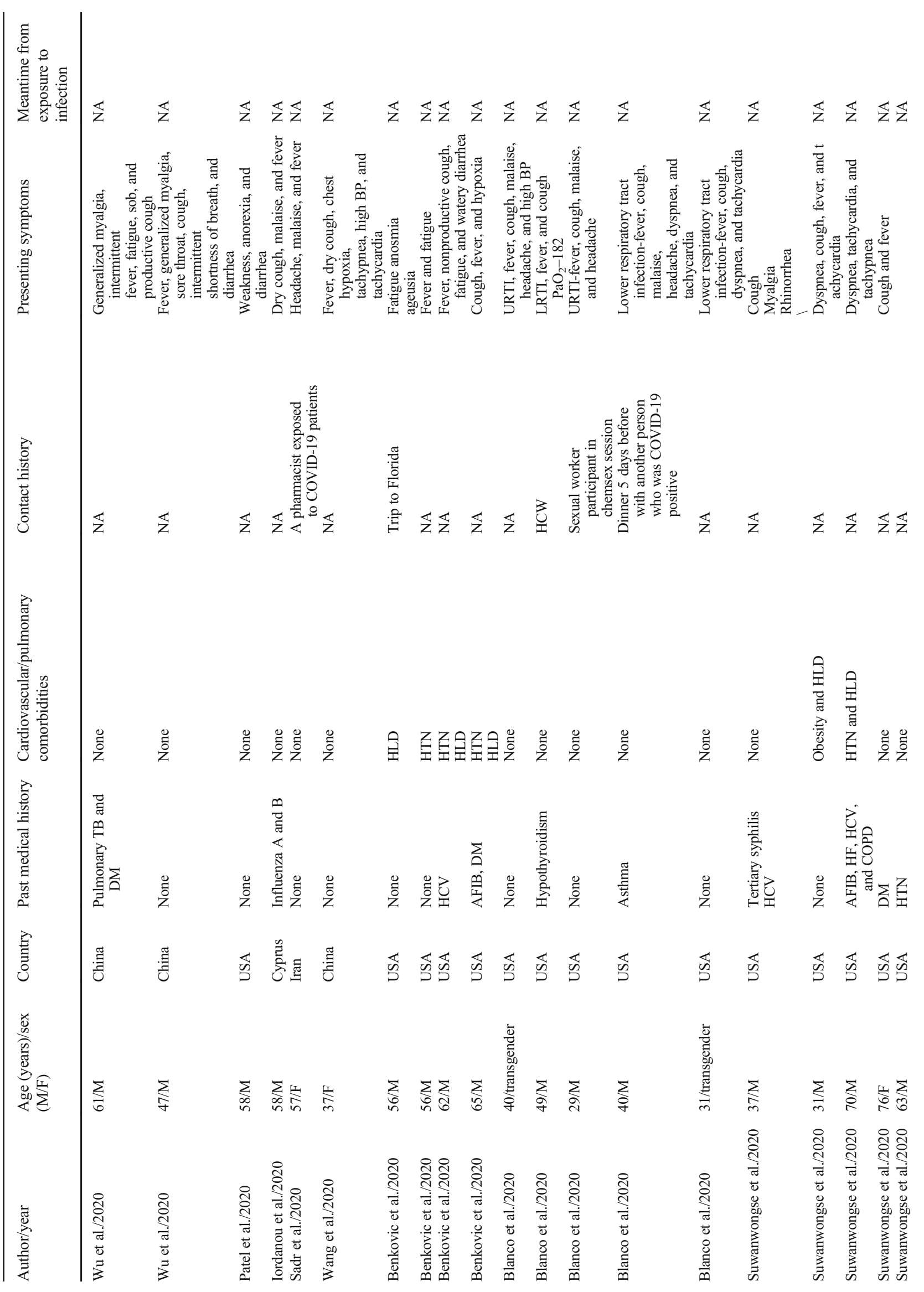




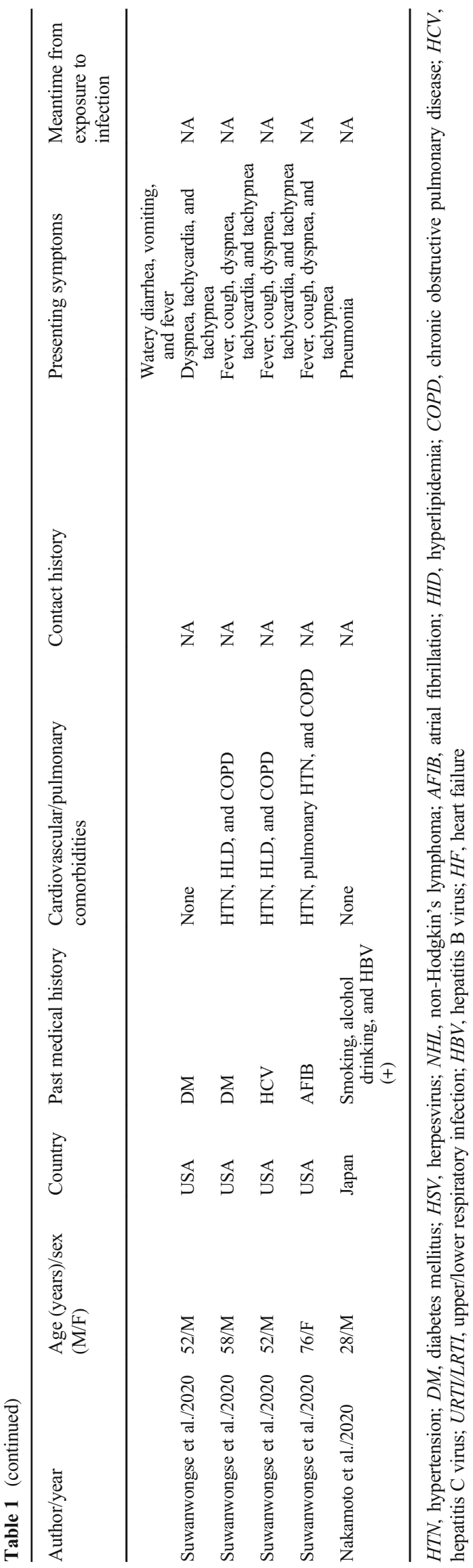

A therapeutic protective role of anti-HIV agents against COVID-19 infections has been reported [15]. Besides this, high mortality $(13.95 \%)$ was reported in these patients. Of those that recovered, 17 (39.53\%) were reported to be taking a combination of tenofovir (TDF) and emtricitabine (FTC) and $3(6.98 \%)$ patients were taking TDF with other combinations of drugs. A study by Amo et al. suggested that HIV-positive patients on treatment with TDF and FTC proved to have a lower risk of COVID-19-related hospitalization [26]. Only 1 out of the 6 patients that did not recover was receiving tenofovir (TDF) and emtricitabine (FTC) as a combination. ART therapy seems to play a crucial role in protecting HIV patients from COVID-19-related hospitalization. However, key challenges have been reported by this high-risk population in timely accessing preand post-exposure prophylaxis during this pandemic [27]. Policymakers in different countries have proposed and implemented a support framework at a different level to support HIV patients during the COVID-19 pandemic $[27,28]$.

\section{Limitations}

Limitations associated with this article should be taken into due consideration while drawing any inference. This review only included the case reports or case series with individual patient-level data so the finding could not be generalized. Furthermore, owing to the small sample size, it is not possible to compare the findings between the deceased and survived groups. Besides, data on CD4 count and viral load were missing in a lot of patients which would make it difficult for any subgroup comparison.

\section{Conclusion}

In our review, we found that HIV patients with COVID-19 had a high burden of HTN and/or DM and were over the age of 50 . The patients who recovered were on a combination of specific ART therapy which was backed up by research in having a protective role against COVID-19 which could have played a role in their recovery. This review gives a glimpse to look deeper into other treatment options such as anti-viral agents like TDF and LPV/r given that the patients over the age of 50 years with HTN and/or DM that did end up recovering were on one or another of these medications. 


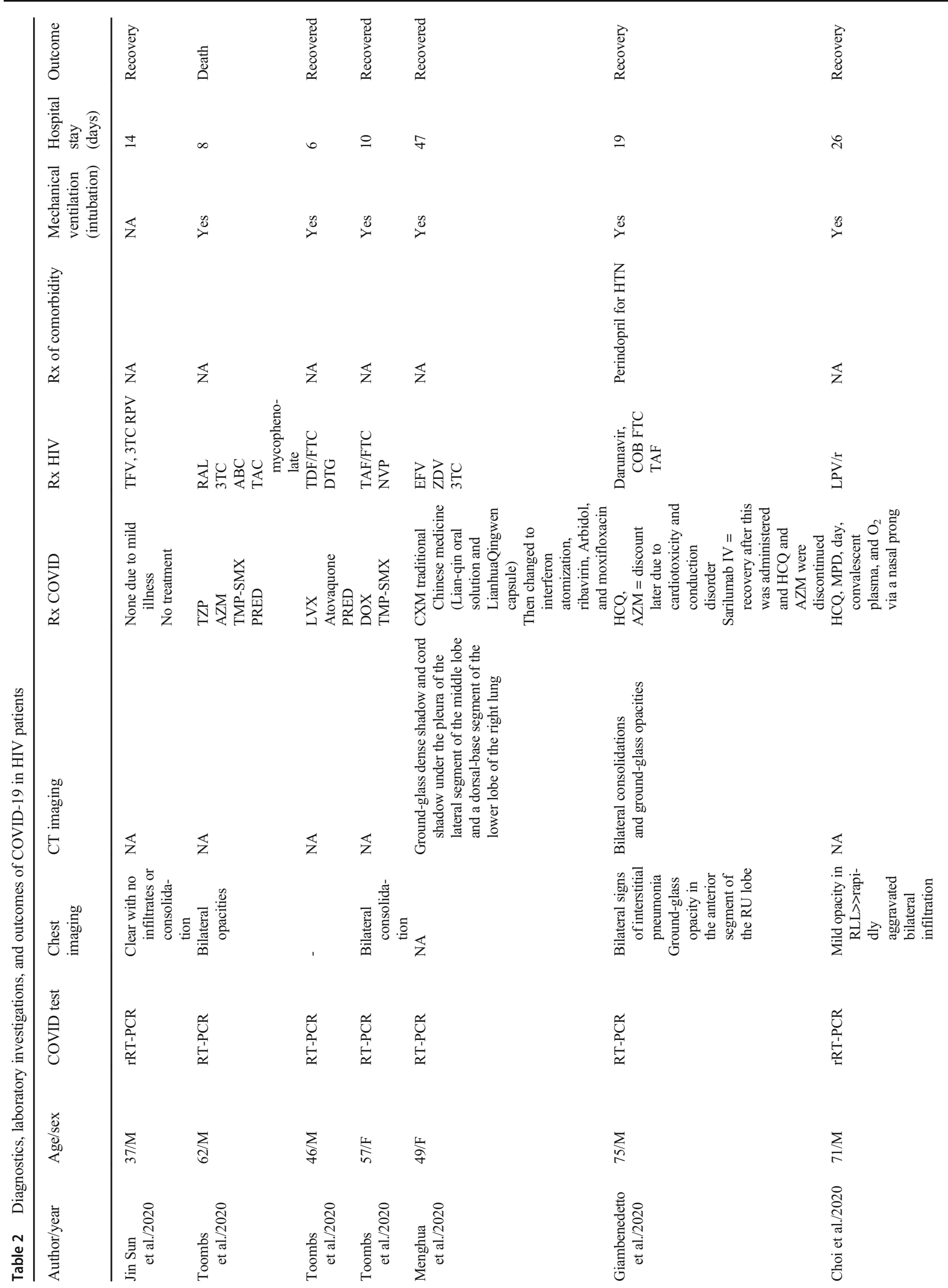




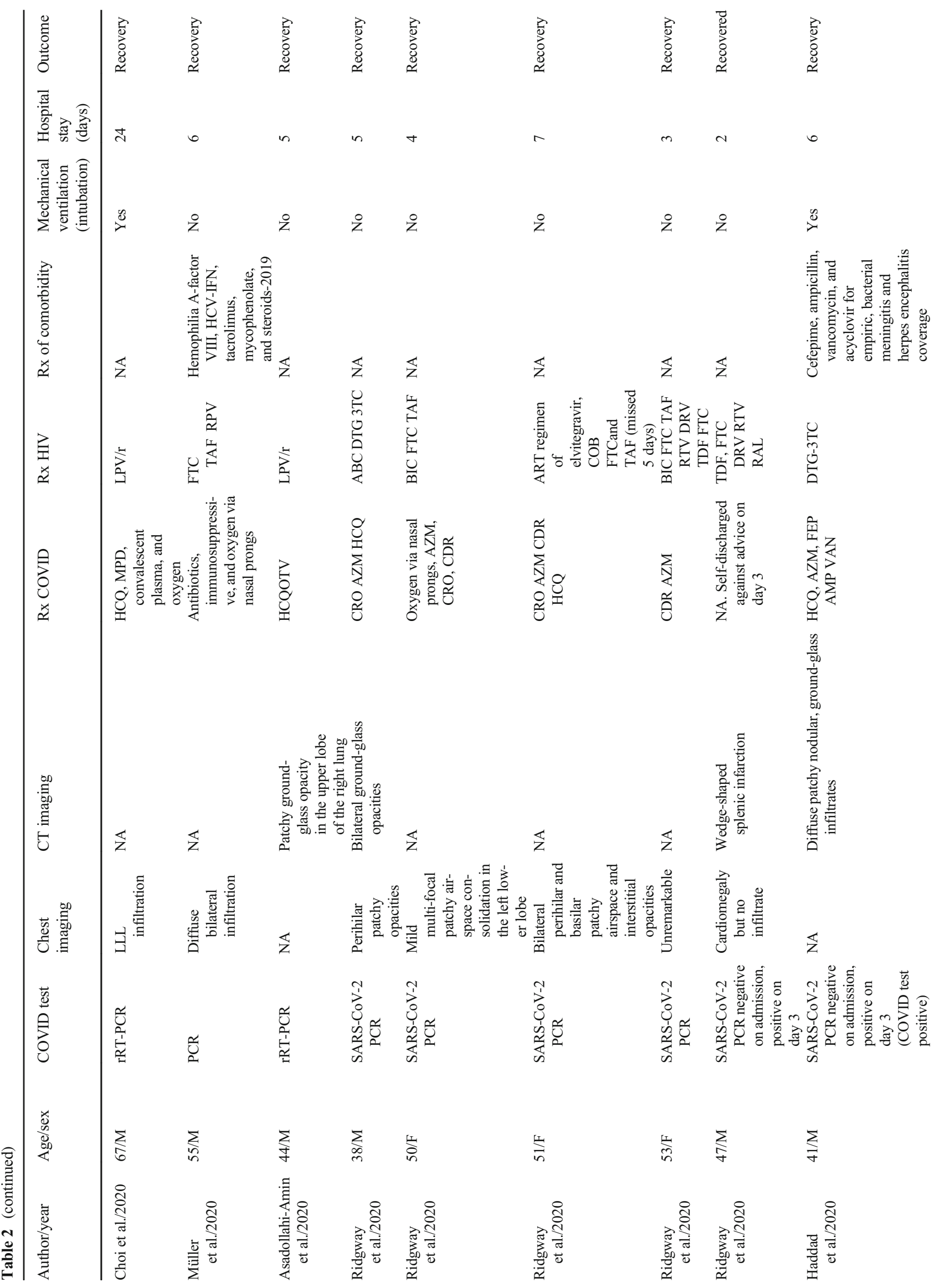




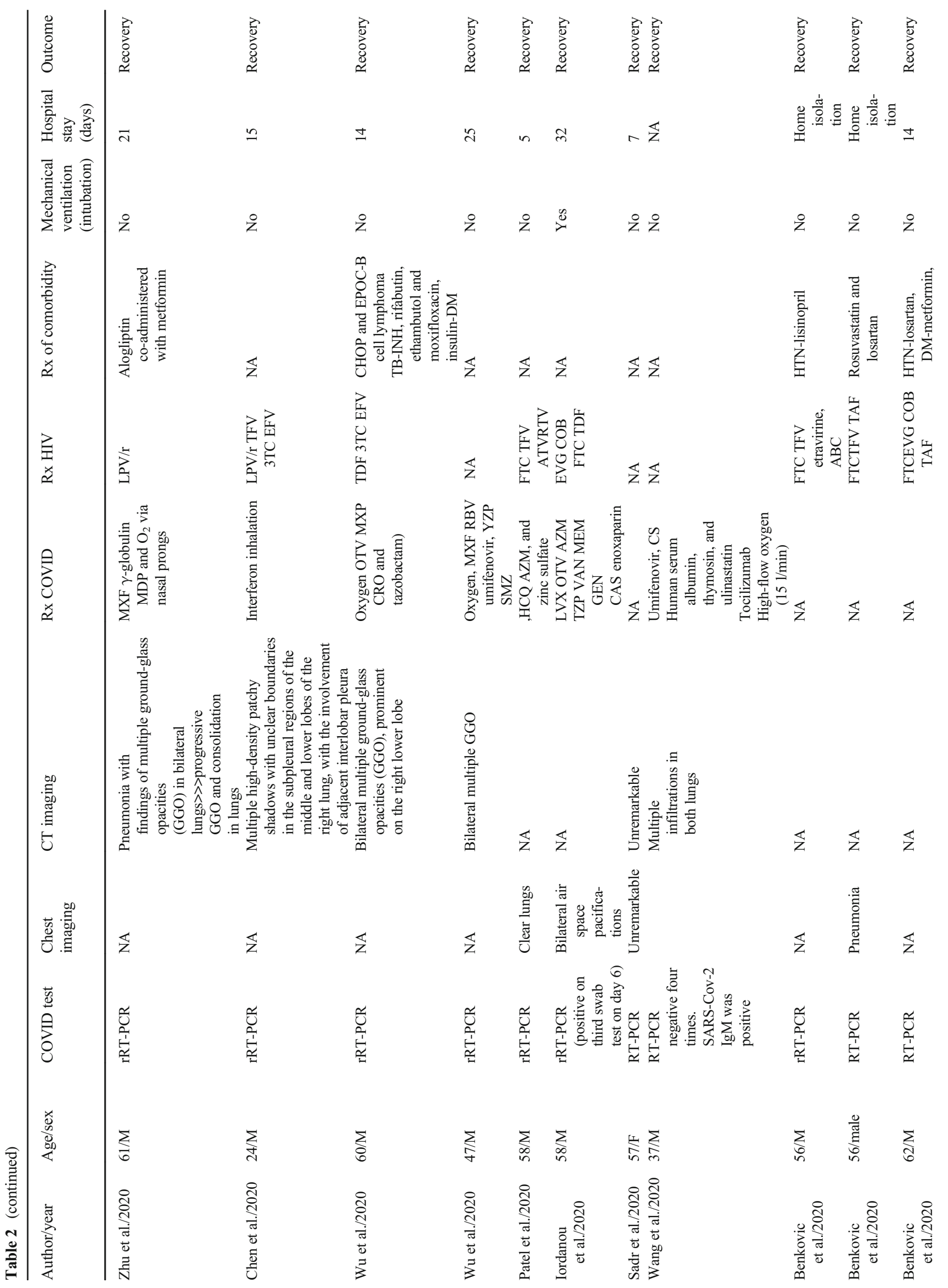




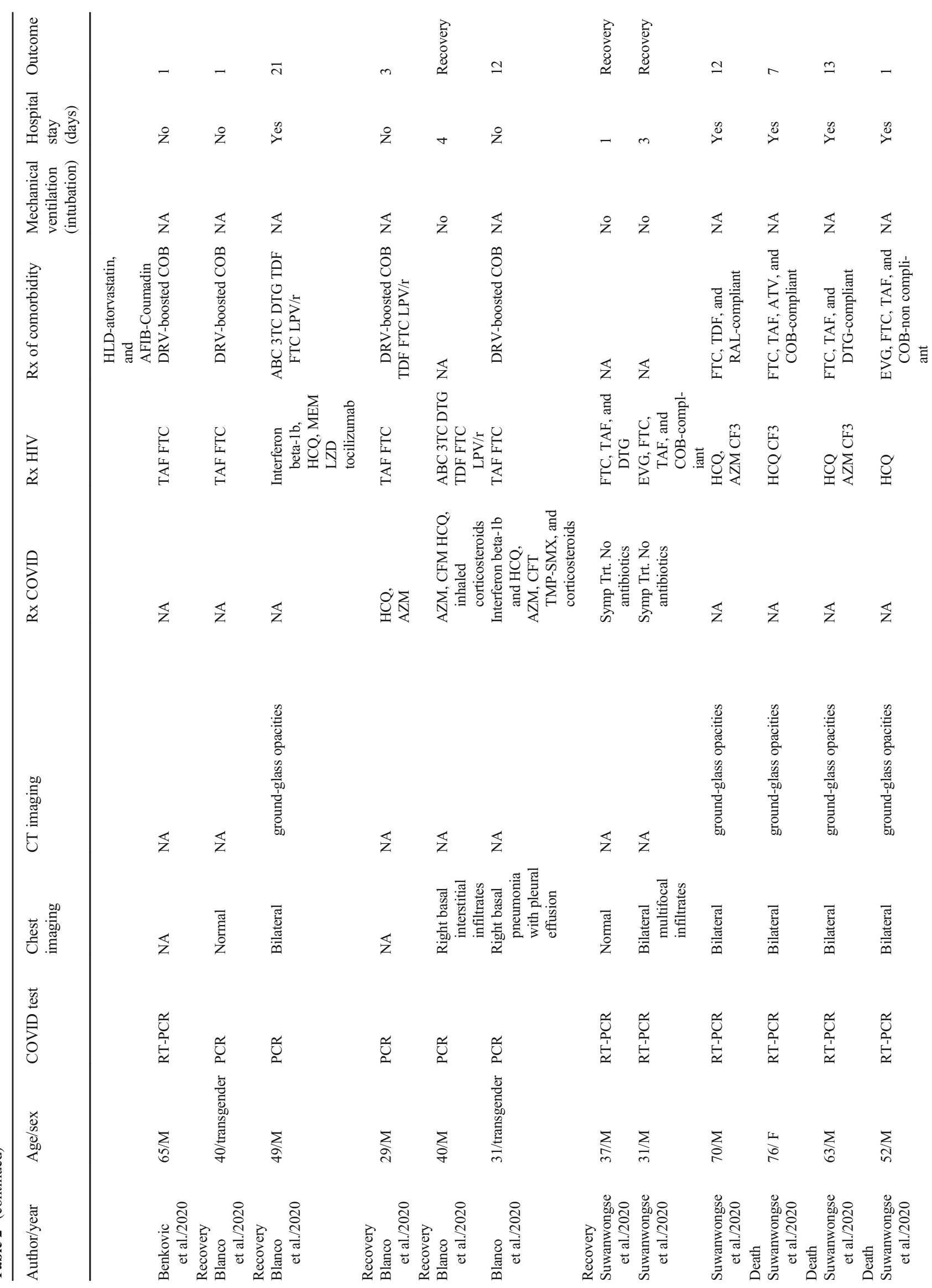




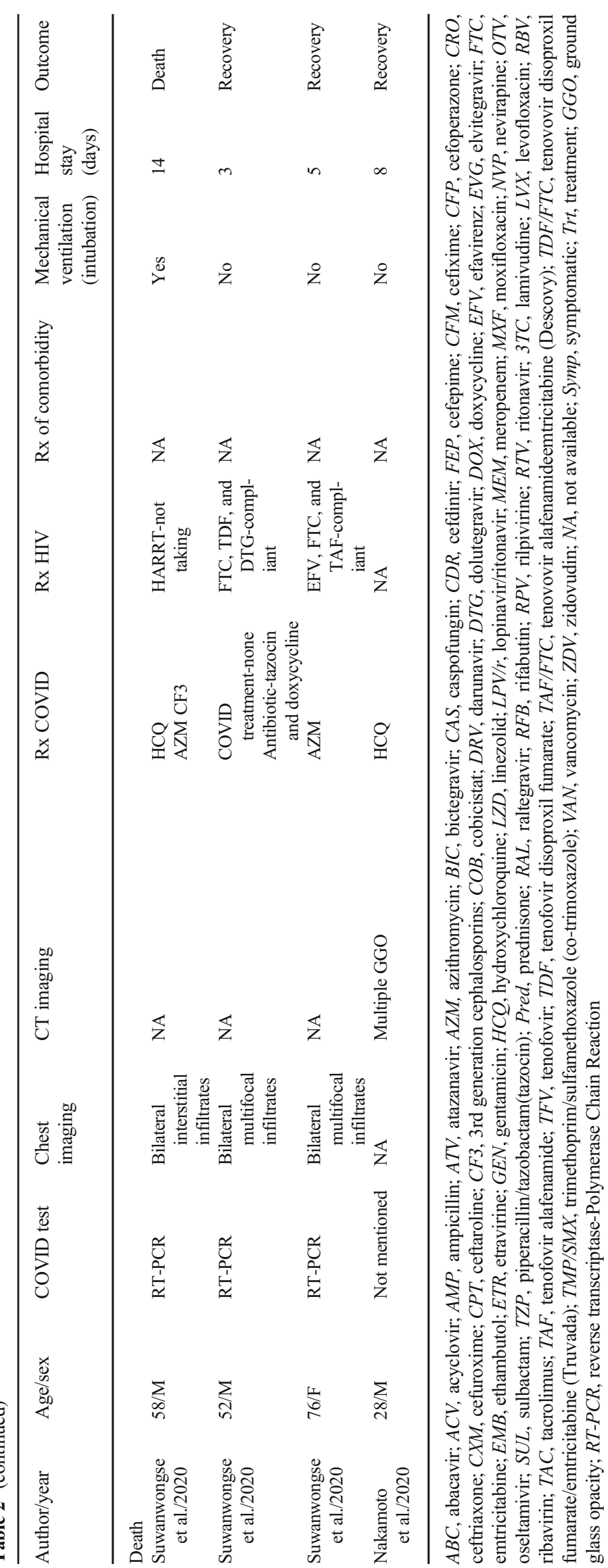




\section{Compliance with Ethical Standards}

Conflict of Interest The authors declare that they have no conflict of interest.

Open Access This article is licensed under a Creative Commons Attribution 4.0 International License, which permits use, sharing, adaptation, distribution and reproduction in any medium or format, as long as you give appropriate credit to the original author(s) and the source, provide a link to the Creative Commons licence, and indicate if changes were made. The images or other third party material in this article are included in the article's Creative Commons licence, unless indicated otherwise in a credit line to the material. If material is not included in the article's Creative Commons licence and your intended use is not permitted by statutory regulation or exceeds the permitted use, you will need to obtain permission directly from the copyright holder. To view a copy of this licence, visit http://creativecommons.org/licenses/by/4.0/.

\section{References}

1. Eaton LA, Kalichman SC. Social and behavioral health responses to COVID-19: lessons learned from four decades of an HIV pandemic. J Behav Med. 2020;43(3):341-5.

2. Jiang H, Zhou Y, Tang W. Maintaining HIV care during the COVID-19 pandemic. Lancet HIV. 2020;7(5):e308-e9.

3. Ridgway JP, Schmitt J, Friedman E, Taylor M, Devlin S, McNulty $\mathrm{M}$, et al. HIV care continuum and COVID-19 outcomes among people living with HIV during the COVID-19 pandemic, Chicago, IL. AIDS Behav. 2020;24(10):2770-2.

4. Ahn JY, Sohn Y, Lee SH, Cho Y, Hyun JH, Baek YJ, et al. Use of convalescent plasma therapy in two COVID-19 patients with acute respiratory distress syndrome in Korea. J Korean Med Sci. 2020;35(14):e149.

5. Sadollahi-Amin A, Hasibi M, Ghadimi F, Rezaei H, SeyedAlinaghi $\mathrm{S}$. Lung involvement found on chest $\mathrm{CT}$ scan in a pre-symptomatic person with SARS-CoV-2 infection: A case report. Tropical Medicine and Infectious Disease. 2020;5(2):56.

6. Benkovic S, Kim M, Sin E, Four cases: Human immunodeficiency virus and novel coronavirus,. Co-infection in patients from Long Island. New York J Med Virol. 2019;2020. https://doi.org/10.1002/ jmv.26029.

7. Blanco JL, Ambrosioni J, Garcia F, Martínez E, Soriano A, Mallolas J, et al. COVID-19 in patients with HIV: clinical case series. Lancet HIV. 2020;7(5):e314-e6.

8. Chen J, Cheng X, Wang R, Zeng X, Computed tomography imaging of an HIV-infected patient with coronavirus disease. COVID19. J Med Virol. 2019;2020. https://doi.org/10.1002/jmv.25879.

9. Di Giambenedetto S, Del Giacomo P, Ciccullo A, Porfidia A, De Matteis G, Cianci R, et al. SARS-CoV-2 infection in a highly experienced person living with HIV. AIDS (London, England). 2020;34(8):1257-8.

10. Haddad S, Tayyar R, Risch L, Churchill G, Fares E, Choe M, et al. Encephalopathy and seizure activity in a COVID-19 well controlled HIV patient. IDCases. 2020;21:e00814.

11. Iordanou S, Koukios D, Matsentidou CT, Markoulaki D, Raftopoulos V. Severe SARS-CoV-2 pneumonia in a 58-year-old patient with HIV: a clinical case report from the Republic of Cyprus. J Med Virol. 2020;92:2361-5.
12. Menghua W, Xin Z, Jianwei L, Yu Z, Qinwei Y. Case report: one case of coronavirus disease 2019 (COVID-19) in a patient coinfected by HIV with a normal CD4(+) T cell count. AIDS Res Ther. 2020;17:46.

13. Rauter M, Krause R, et al. Recovery from COVID-19 following hepatitis $\mathrm{C}$, human immunodeficiency virus infection and liver transplantation. Am J Transplant Off J Am Soc Transplant Am Soc Transplant Surg. 2020. https://doi.org/10.1111/ajt.16107.

14. Nakamoto T, Kutsuna S, Yanagawa Y, Kanda K, Okuhama A, Akiyama $\mathrm{Y}$, et al. A case of SARS-CoV-2 infection in an untreated HIV patient in Tokyo. Japan J Med Virol. 2020. https://doi.org/10. 1002/jmv.26102.

15. Patel RH, Pella PM. COVID-19 in a patient with HIV infection. J Med Virol. 2020;92:2356-7.

16. Ridgway JP, Farley B, Benoit JL, Frohne C, Hazra A, Pettit N, et al. A case series of five people living with HIV hospitalized with COVID-19 in Chicago. Illinois AIDS Patient Care STDs. 2020;34(8):331-5.

17. Sadr S, SeyedAlinaghi S, Ghiasvand F, Hassan Nezhad M, Javadian N, Hossienzade R, et al. Isolated severe thrombocytopenia in a patient with COVID-19: a case report. IDCases. 2020;21: e00820.

18. Sun LJ, Wong SXL, Gollamudi S. A case of HIV and SARS-CoV2 co-infection in Singapore. J Acquir Immune Defic Syndr. 2020;84(4):e23-e4.

19. Suwanwongse K, Shabarek N. Clinical features and outcome of HIV/SARS-CoV-2 co-infected patients in the Bronx, New York City. J Med Virol. 2020;92:2387-9.

20. Toombs JM, Van den Abbeele K, Democratis J, Merricks R, Mandal AKJ, Missouris CG. COVID-19 in three people living with HIV in the United Kingdom. J Med Virol. 2020. https://doi.org/10. 1002/jmv.26178.

21. Wang M, Luo L, Bu H, Xia H. One case of coronavirus disease 2019 (COVID-19) in a patient co-infected by HIV with a low CD4(+) T-cell count. Int J Infect Dis. 2020;96:148-50.

22. Wu Q, Chen T, Zhang H. Recovery from COVID-19 in two patients with coexisted HIV infection. J Med Virol. 2020. https://doi. org/10.1002/jmv.26006.

23. Zhu F, Cao Y, Xu S, Zhou M. Co-infection of SARS-CoV-2 and HIV in a patient in Wuhan City. China J Med Virol. 2020;92(6): 529-30.

24. Shahid Z, Kalayanamitra R, McClafferty B, Kepko D, Ramgobin D, Patel R, et al. COVID-19 and older adults: what we know. J Am Geriatr Soc. 2020;68(5):926-9.

25. Yu C, Zhang Z, Guo Y, Shi J, Pei G, Yao Y, et al. Lopinavir/ ritonavir is associated with pneumonia resolution in COVID-19 patients with influenza coinfection: a retrospective matched-pair cohort study. J Med Virol. 2020. https://doi.org/10.1002/jmv. 26260.

26. Del Amo J, Polo R, Moreno S, Díaz A, Martínez E, Arribas JR, et al. Incidence and severity of COVID-19 in HIV-positive persons receiving antiretroviral therapy: a cohort study. Ann Intern Med. 2020;173(7):536-41.

27. Wang H. HIV care during the coronavirus disease-2019 pandemic in Shenzhen, China. Curr Opin HIV AIDS. 2020;15(6):341-4.

28. Holtgrave DR, Valdiserri RO, Kalichman SC, Del Rio C, Thompson M. Core elements of a national COVID-19 strategy: lessons learned from the US national HIV/AIDS strategy. AIDS Behav. 2020;1-4. https://doi.org/10.1007/s10461-020-03045-3

Publisher's Note Springer Nature remains neutral with regard to jurisdictional claims in published maps and institutional affiliations. 